\title{
\#ScienceSunday: Using Face Book as a Tool to Promote Science
}

\author{
Voltaire Mallari Mistades
}

\begin{abstract}
The growth of Internet use in education has prompted a variety of ways by which technology is used to enhance the students' learning experience. Social networking sites have been used as an alternative to the traditional ways that Information and Communications Technology (ICT) have been used for online learning. Given that FaceBook is acknowledged as the world's largest online networking site, this article presents how FaceBook was used by the author to disseminate information and awareness about Science. In particular, the themes and topics used as the basis of putting structure in the FaceBook posts will be discussed. The author's experience reveals that being engaged in social media online encourages interaction and collaboration. FaceBook has been a positive tool in promoting science.
\end{abstract}

Index Terms - Education institution, higher education, social networking site, science Sunday special feature.

\section{INTRODUCTION}

Information and Communications Technology (ICT) has now become an integral part of people's day-to-day life. The growing use of Internet in education has challenged and encouraged educators to find ways by which this technology may be used to enhance the teaching-learning experience. In two papers authored by Allen and Seaman [1], [2] they reported the growing use of the Internet in education, particularly by Higher Education Institutions (HEIs) in the United States that offer online courses. The students who were surveyed in the study described their experience in the online course as having learning outcomes comparable to traditional face-to-face classrooms. This positive experience is affirmed by the study conducted by O' Shea, Stone, and Delahunty [3] among undergraduate and postgraduate students from Higher Education Institutions in Australia

The Internet has made education more accessible to a wider number of people through the massive open online courses (MOOCs). MOOCs are online courses aimed at unlimited participation and open access. As an off-shoot of distance education, MOOCs were first introduced in 2008, with uploaded lectures, a set of reading materials, and a list of problems for the learners to work on. An interactive user forum also provided the interaction between the community of learners engaged in MOOCs.

Manuscript received May 3, 2015; revised June 5, 2015. This work was supported in part by the DLSU Science Foundation, the Office of the Vice Chancellor for Academics, and the Office of the Vice Chancellor for Research and Innovation, De La Salle University.

V. M. Mistades is with the Science Education Department of the $\mathrm{Br}$ Andrew Gonzalez FSC College of Education, De La Salle University, 2401 Taft Avenue, Manila, 0922, Philippines (e-mail: voltaire.mistades@dlsu.edu.ph).
MOOCs have now emerged as a popular mode of learning, owing to its foundational educational theory of Connectivism. As posited by Siemens [4], the Theory of Connectivism considers learning as an extension of a personal network through which participants learn, share knowledge, and comprehend. Since MOOCs not only allow participants to see and hear, but also to participate and collaborate, the relationship between students and teachers, academia, and the community-at-large has changed due to the broad and diverse virtual space offered by the digital learning platform. Toven-Lindsey, Rhoads, and Lozano [5] have shown how MOOCs have provided students with high-quality, collaborative learning experiences. The findings of their study suggest that the range of pedagogical practices currently used in MOOCs leans toward an objectivist-individual approach, with some efforts to incorporate more constructivist and group-oriented approaches.

The use of social networking sites as an alternative to the traditional ways that ICT have been used for online learning has been observed by Bateman and Willems [6]. They have noted that FaceBook has been increasingly used as a channel for communication with students in Higher Education Institutions. Various authors have cited the different roles played by social networking sites in education, including that of helping students develop and maintain social capital [7], forming a place where students can collaborate and communicate with their peers [8], creating a community of learners, particularly for groups of geographically-dispersed students [6], and that of encouraging lifelong learning [9]. Internet access of Persons with Disabilities (PWDs) has also been "bridged" by FaceBook [7].

In one study, closed FaceBook groups were used as an addition to the more traditional discussion boards found in Learning Management Systems (LMS) such as Blackboard and Moodle. Kent [10] reported that the addition of FaceBook as a discussion forum to an existing online and blended learning unit greatly increased the level of student activity, both in absolute terms and also sustained over the full study period, instead of just being limited to a few points of peak activity followed by relative inactivity. This increased level of student activity may be attributed to its user interface, as Grey, Lucas, and Kennedy [8] reported that FaceBook is easier to use compared with many existing forums in traditional Learning Management Systems (LMS) of Higher Education Institutions.

However, some scholars have stated a contradictory stance, arguing that FaceBook should be seen as a "student-only space" [11]. Teclehaimanot and Hickman [11] put forward their position that students believe FaceBook is an inappropriate place for interacting with the teaching staff. 
Further, it has been reported that students would resist members of the teaching faculty from accessing their essentially private FaceBook space [12].

There are also anecdotal evidences [11] that teachers do not want to use Facebook in education due to concerns that students would find it inappropriate. Grey, Lucas, and Kennedy [8] have cautioned the accessibility issues for students who are not part of the network. An additional concern would be the students who, for a variety of reasons, may not wish to engage in social networks [13].

Having presented both the advantages and disadvantages of the use of social networks in education, it is, however, a given fact that FaceBook is acknowledged as the world's largest online networking site, with over one billion users as of end of 2013 [14], with estimates of close to 1.7 billion users as of 2015 [15]. Thus, there is a need to leverage this resource where communities are created and maintained. Roblyer et al. [16] provides us with the reason for doing so, "Students ... [are] much more open to the idea of using FaceBook instructionally than do faculty". And, as Palloff and Pratt [17] note, "The positive aspects of using these forms of technology, however, may outweigh the negatives".

This article presents how FaceBook was used to disseminate information and awareness about Science. In particular, the themes and topics used as the basis of putting structure in the FaceBook posts will be discussed.

\section{DISCUSSION}

The \#ScienceSunday FaceBook posts started as a way of sharing Science trivia, which included highlighting significant events happening in the world of Science, commemorating the birth anniversary of scientists with their significant contribution to society, and providing general facts and knowledge about Science.

Fig. 1 and Fig. 2 are sample FaceBook screenshots of the \#ScienceSunday posts during the early stages of the project, September 2014

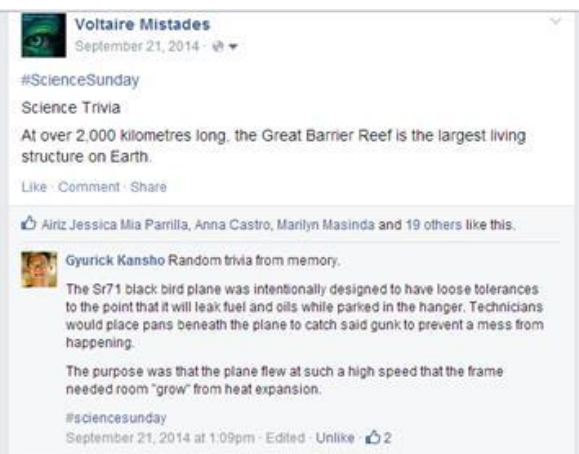

Fig. 1. \#ScienceSunday trivia about the Great Barrier Reef.

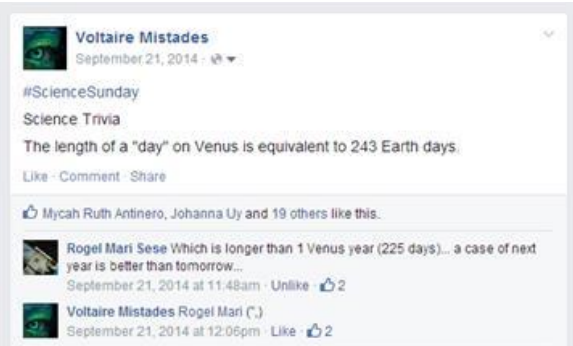

Fig. 2. \#ScienceSunday trivia about the planet Venus.
As the year 2015 was about to begin, a special feature on fifteen (15) significant events to look forward to in 2015 was the theme of the last set of \#ScienceSunday posts for the year 2014. Fig. 3 presents a screenshot of the console of the time travel machine in the movie, Back to the Future.

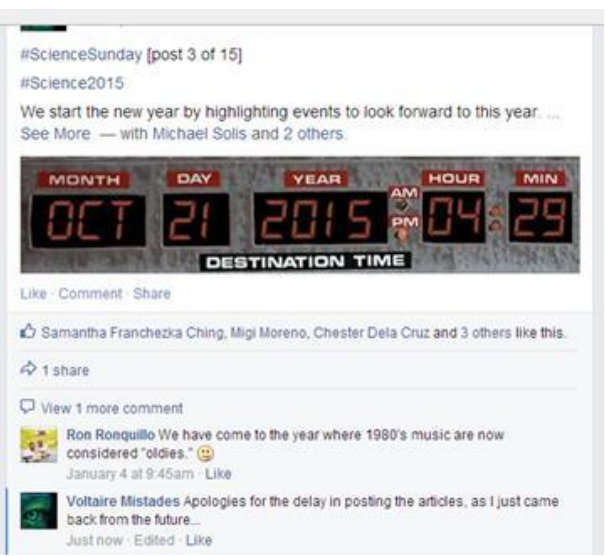

Fig. 3. \#ScienceSunday tribute post to the movie, back to the future.

To put structure in the \#ScienceSunday posts, the author has assigned the first Sunday of each month to feature scientists who were born on that month. Fig. 4 to Fig. 7 are sample screenshots of the \#ScienceSunday posts highlighting famous scientists.

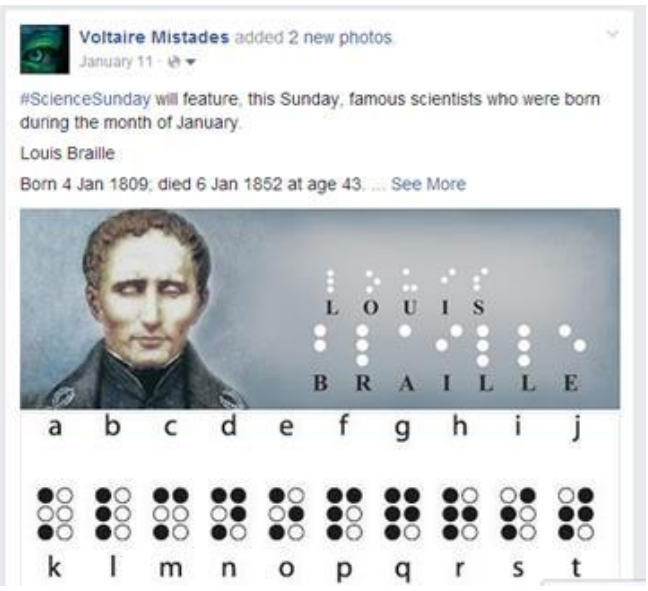

Fig. 4. \#ScienceSunday January birthday celebrant, Louis Braille.

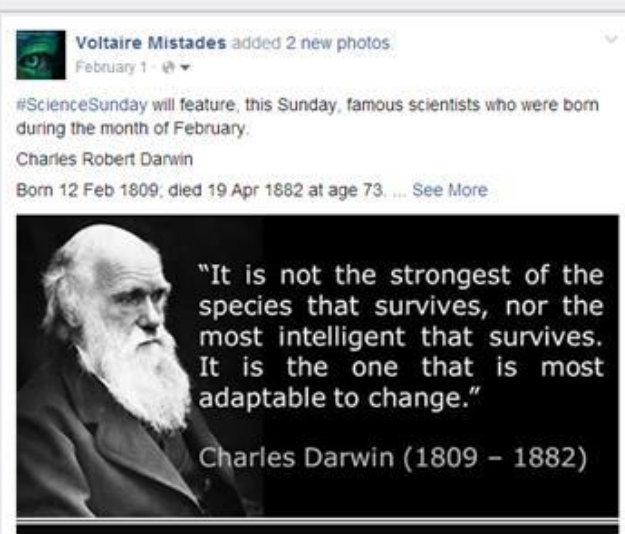

Fig. 5. \#ScienceSunday February birthday celebrant, Charles Darwin.

To have a variety in the presentation, some \#ScienceSunday posts would include famous quotations attributed to the featured scientist, as in the case of Fig. 5 ["It is not the strongest of the species that survives, nor the most intelligent that survives. It is the one that is most adaptable to 
change."] and Fig. 7 ["I doubt therefore I think, I think therefore I am."]

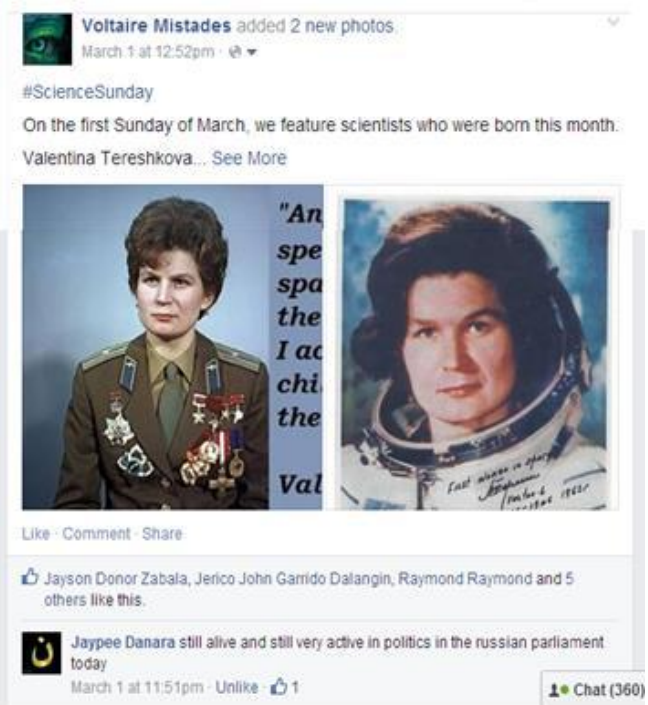

Fig. 6. \#ScienceSunday March birthday celebrant, Valentina Tereshkova.

Voltaire Mistades added 5 new photos.
"ScienceSunday
On the first Sunday of March, we feature scientists who were born this month.
René Descartes
Born 31 Mar 1596; died 11 Feb 1650 at age 53
French philosopher and mathematician who is known as "the Father of
Modern Philosophy". His work, La Géométrie, includes his application of
algebra to geometry from which we now have Cartesian geometry. During
$1620-1628$, Descartes travelled through Europe, then settled in Holland.
Soon after, he began work on his first major treatise on physics. "Le Monde.
ou Traite de la Lumierre". This work was near completion when news that
Gallieo was condemned to house arrest reached him. He decided not to
publish that work during his lifetime. Later, he turned to philosophy, one of
the first to oppose scholastic Aristotelianism, he began by methodically
doubting knowledge based on authority, the senses, and reason. His most
famous quote is "l think, therefore I am".
20 Chat (372)

Fig. 7. \#ScienceSunday March birthday celebrant, Rene Descartes

Fig. 6 shows how the interaction / engagement occurs through the comments box of the FaceBook post, "still alive and still very active in Russian parliament today".

The last Sunday of each month is designated to highlight important scientific historical events that occurred during the month. For example, Fig. 8 presents a screenshot of the re-discovery of Tutankhamen's tomb on November 1922.

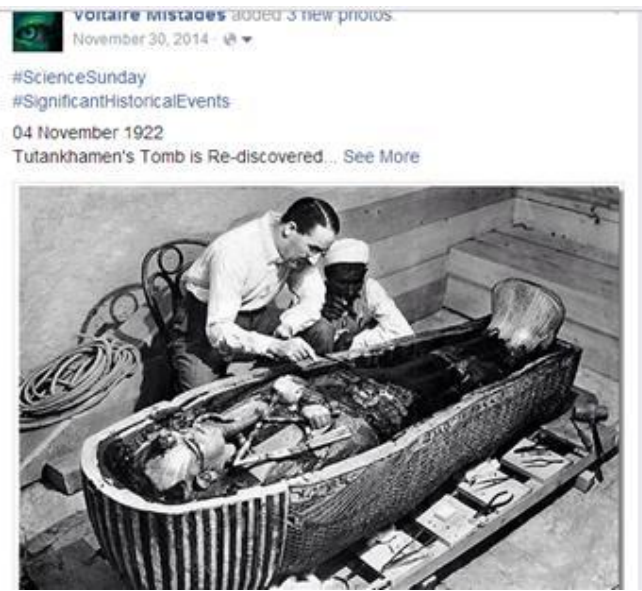

Fig. 8. \#ScienceSunday feature on the re-discovery of Tutankhamen's tomb.

The engagement and interaction with FaceBook readers / viewers may be gauged by the number of "likes" and posted comments. One such \#ScienceSunday feedback (Fig. 9) came from a former student who gave an interesting photo comment after reading a \#ScienceSunday post about Newton's Laws of Motion.

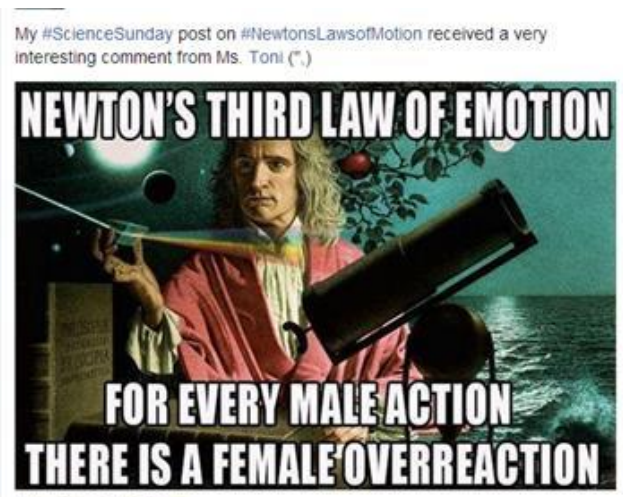

$$
\text { B Edwin Caliwan Mina, Rosanna Luz Feliciano Valerio, Airiz Jessica Mia Pamilla and } 25
$$

Fig. 9. Photo Comment received regarding \#ScienceSunday feature on Newton's Laws of Motion.

The more popular \#ScienceSunday posts had been the ones posted during the second and third Sundays of the month, which is thematic in its content. For example, Fig. 10, which was posted during the Cheer Dance Competition of the University Athletic Association of the Philippines (UAAP) generated 36 "likes".

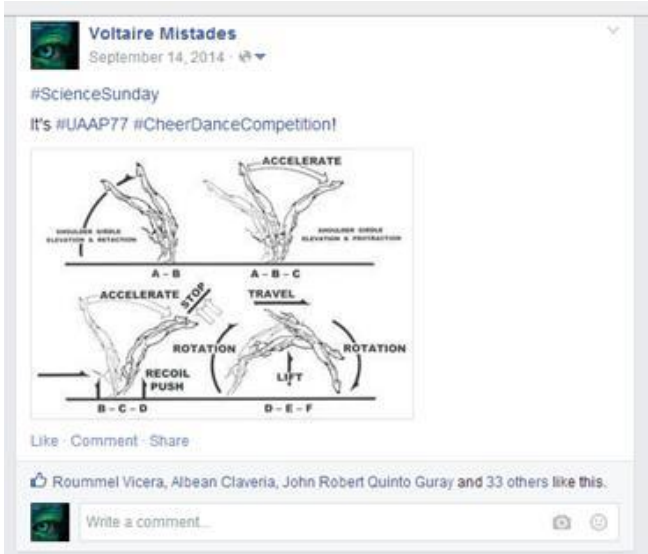

Fig. 10. \#ScienceSunday special feature on the Science of Cheer Dancing.

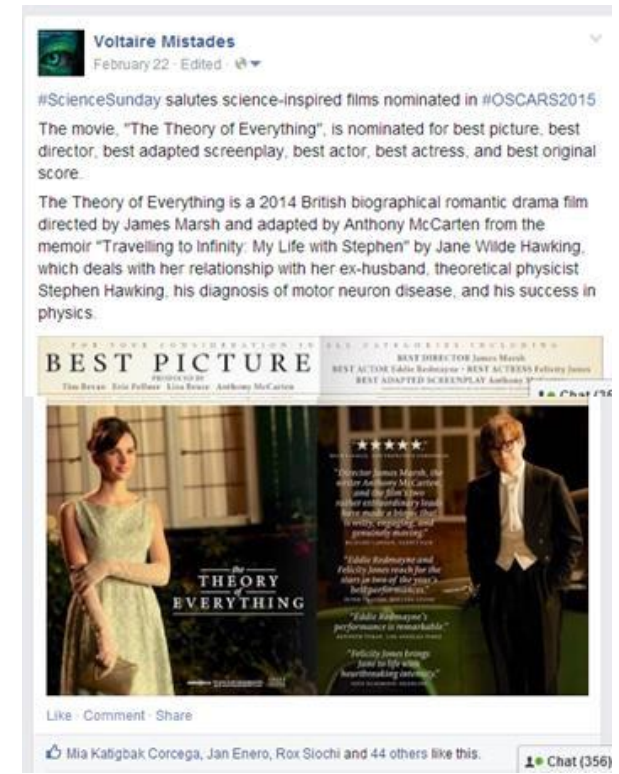

Fig. 11. \#ScienceSunday special feature on Science-inspired movies. 
A couple of recent movies that had Science-oriented themes made it to the list of nominees for the prestigious OSCAR awards 2015. The film, Theory of Everything., which was inspired by the life of theoretical physicist Stephen Hawking, received a Best Picture nomination. When it was featured in \#ScienceSunday (Fig. 11), the FaceBook post generated 47 "likes".

The \#ScienceSunday posts had also been utilized to highlight the relationship between Faith and Science. In particular, the visit to the Philippines of Pope Francis, the acknowledged leader of the Roman Catholic Church, who, interestingly, has a background in Chemistry, generated 58 "likes" and 35 "shares" for this particular \#ScienceSunday post (Fig. 12).

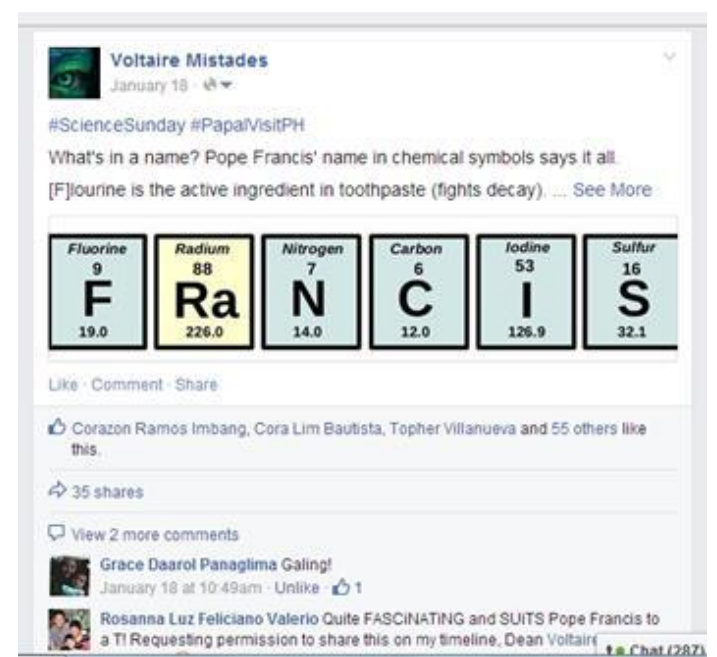

Fig. 12. \#ScienceSunday special feature on the visit of Pope Francis to the Philippines.

\section{CONCLUSION}

Educators would have to be in the world where our learners are. The Internet is a vast area where educators could engage the learners. Aydin [18] has noted that "[since] Facebook is very popular among students, the potential of Facebook as an educational environment should be channeled into educational practices and research" (page 1101). The \#ScienceSunday FaceBook posts has shown that being engaged online encourages interaction and collaboration.

\section{REFERENCES}

[1] I. E. Allen and J. Seaman. (2011). Going the distance: Online education in the United States 2011. [Online]. Available: http://www.onlinelearningsurvey.com/reports/goingthedistance.pdf

[2] I. E. Allen and J. Seaman. (2010). Class differences: Online education in the United States 2010. [Online]. Available: http://sloanconsortium.org/sites/default/files/class_differences.pdf

[3] S. O' Shea, C. Stone, and J. Delahunty, "I 'feel' like I am at university even though I am online," Exploring How Students Narrate Their Engagement with Higher Education Institutions in an Online Learning Environment, Distance Education, March 2015.
[4] G. Siemens, "Connectivism: A learning theory for the digital age," International Journal of Instructional Technology and Distance Learning, vol. 2, no. 1, pp. 3-10, 2004.

[5] B. Toven-Lindsey, R. A. Rhoads, and J. B. Lozano, "Virtually unlimited classrooms: Pedagogical practices in massive open online courses," The Internet and Higher Education, vol. 24, pp. 1-12, January 2015.

[6] D. Bateman and J. Willems, "Facing off: Facebook and higher education," Misbehavior Online in Higher Education: Cutting-Edge Technologies in Higher Education, vol. 5, pp. 53-79, 2012.

[7] N. B. Ellison, C. Steinfield, and C. Lampe, "The benefits of Facebook 'friends': Social capital and college students' use of online social networking sites," Journal of Computer-Mediated Communication, vol. 12, no. 4, pp. 1143-1168, 2007.

[8] K. Gray, A. Lucas, and G. Kennedy, "Medical students' use of Facebook to support learning: Insights from four case studies," Medical Teacher, vol. 32, no. 12, pp. 971-980, 2010.

[9] A. J. Lenartz, "Establishing guidelines for the use of social media in higher education," Misbehavior Online in Higher education: Cutting-Edge Technologies in Higher Education, vol. 5, Emerald Group Publishing Limited, pp. 333-353, 2012.

[10] M. Kent, "Changing the conversation: Facebook as a venue for online class discussion in higher education," MERLOT Journal of Online Learning and Teaching, vol. 9, no. 4, 2013.

[11] B. Teclehaimanot and T. Hickman, "Student-teacher interaction on Facebook: What students find appropriate," TechTrends: Linking Research and Practice to Improve Learning, vol. 55, no. 3, pp. 19-30, 2011.

[12] G. Best, D. Hajzler, G. Pancini, and D. Tout, "Being 'dumped' from Facebook: Negotiating issues of boundaries and identity in an online social networking space," Journal of Peer Learning, vol. 4, no. 1, pp. 24-36, 2011.

[13] J. McCarthy, "Blended learning environments: Using social networking sites to enhance the first-year experience," Australasian Journal of Educational Technology, vol. 26, no. 6, pp. 729-740, 2010.

[14] J. Constine. (2013). Facebook's growth since IPO in 12 big numbers. [Online]. http://techcrunch.com/2013/05/17/facebook-growth/

[15] Y. He, "Description of a cloud based private social network security scheme," International Journal of Information and Education Technology, vol. 5, no. 7, pp. 532-537, 2015.

[16] M. D. Roblyer et al., "Findings on Facebook in higher education: A comparison of college faculty and student uses and perceptions of social networking sites," The Internet and Higher Education, vol. 13, no. 3, pp. 134-140, 2010.

[17] R. M. Palloff and K. Pratt. (2009). Web 2.0 technologies and community building online. The 25th Annual Conference on Distance Teaching \& Learning. Madison, Wisconsin. [Online]. Available: http://www.uwex.edu/disted/conference/Resource_library/proceeding s/09_20002.pdf

[18] S. Aydin, "A review of research on Facebook as an educational environment," Education Technology Research and Development, vol. 60, pp. 1093-1106, 2012.

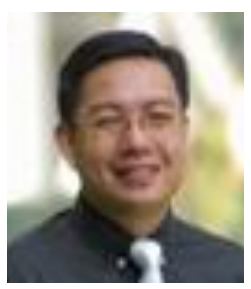

Voltaire M. Mistades was born in Manila in June 1972. He earned the Ph.D. in science education from De La Salle University, Manila, Philippines in 2011. $\mathrm{He}$ is currently an associate professor of the $\mathrm{Br}$. Andrew Gonzalez FSC College of Education at the De La Salle University, Manila, Philippines. His research interests include physics education, values education, and learning and teaching in higher education. Dr. Mistades is a member of the Samahang Pisika ng Pilipinas (Physics Society of the Philippines). 